\title{
Norovirus Infection in Harbor Porpoises
}

\author{
Miranda de Graaf, Rogier Bodewes, ${ }^{1}$ \\ Cornelis E. van Elk, Marco van de Bildt, \\ Sarah Getu, Georgina I. Aron, \\ Georges M.G.M. Verjans, \\ Albert D.M.E. Osterhaus, \\ Judith M.A. van den Brand, \\ Thijs Kuiken, Marion P.G. Koopmans
}

A norovirus was detected in harbor porpoises, a previously unknown host for norovirus. This norovirus had low similarity to any known norovirus. Viral RNA was detected primarily in intestinal tissue, and specific serum antibodies were detected in $8(24 \%)$ of 34 harbor porpoises from the North Sea.

$\mathrm{N}$ oroviruses have been detected in humans, cats, dogs, pigs, sheep, cattle, sea lions, rodents, and bats (1-4). In humans, norovirus is a leading cause of gastroenteritis (1). Seven different norovirus genogroups have been described for the norovirus genus (1) that can be further subdivided in $\approx 30$ genotypes. Noroviruses comprise a single-strand positive-sense RNA genome that is divided into 3 open reading frames (ORFs). Recombination among different genotypes is frequently observed for human noroviruses, most commonly near the junction of ORF1 and ORF2, leading to a recommendation for multilocus genotyping (5). Surprisingly, recombinant human noroviruses regularly contain previously undetected ORF1 sequences, which raises questions about the reservoirs of these viruses.

Noroviruses can spread through the fecal-oral route, and sewage contamination in coastal environments can result in contamination of shellfish, such as oysters. Oysters filter several liters of seawater daily and contain histo-blood group antigens resembling those of humans. These antigens can be specifically bound by noroviruses, resulting in bioaccumulation (6); as a result, eating oysters is linked to foodborne norovirus outbreaks in humans (7). This mode of transmission, however, could expose humans to viruses from other animal reservoirs, such as marine mammals, and vice versa.

Author affiliations: Erasmus Medical Centre, Rotterdam, the

Netherlands (M. de Graaf, R. Bodewes, C.E. van Elk, M. van de Bildt, S. Getu, G.I. Aron, G.M.G.M. Verjans, J.M.A. van den Brand, T. Kuiken, M.P.G. Koopmans); Dolphinarium Harderwijk, Harderwijk, the Netherlands (C.E. van Elk); SOS Dolphin Foundation, Harderwijk, the Netherlands (C.E. van Elk); University of Veterinary Medicine, Hannover, Germany (A.D.M.E. Osterhaus)

\section{The Study}

A juvenile male harbor porpoise (Phocoena phocoena) $\approx 10.5$ months of age was found alive on the coast of the Netherlands on May 10, 2012, and was transported to the SOS Dolphin Foundation (Harderwijk, the Netherlands) for rehabilitation (online Technical Appendix, http://wwwnc. cdc.gov/EID/article/23/1/16-1081-Techapp1.pdf). Important clinical signs at the rehabilitation center were anorexia, labored breathing, and disorientation. The animal showed no evidence of gastrointestinal disease, such as vomiting or diarrhea. Eight days after arrival in the rehabilitation center, the animal was euthanized because of the severity of clinical signs, and necropsy was performed according to standard procedures (8). The main pathology findings were bronchopneumonia associated with lungworm infection and encephalitis and hepatitis of unknown cause. The intestine did not show significant lesions macroscopically; microscopically, the enterocytes at the luminal surface of the intestine had sloughed into the lumen as a result of freeze-thaw artifact. The cells lining the intestinal crypts consisted of a mixture of enterocytes and mucus cells. The proportion of mucus cells increased progressively toward the end of the intestine. The lamina propria was infiltrated diffusely with a moderate number of lymphocytes, plasma cells, and eosinophils. This infiltrate was considered normal for this species.

In the frame of a research program focusing on the identification of new viruses in possible reservoir hosts, we collected fecal material and performed random PCR in combination with 454-sequencing as described previously (9). This analysis resulted in 5,774 reads, of which 88 reads were most closely related to the norovirus genus, as determined by blastn and blastx analysis (10). Other reads that were most similar to viral genomes were most closely related to a coronavirus (16 reads [35\%-94\% nt identity]), salmon calicivirus (3 reads $[11 \%-69 \%$ nt identity]), and porcine anello virus ( 1 read [ $91 \%$ nt identity], 2 reads [36\% amino acid identity]). The harbor porpoise norovirus (HPNV) sequence was confirmed by Sanger sequencing (6,293 nt; GenBank accession no. KP987888) by using specific primers and comprising 3 ORFs, the partial ORF1 encoding the putative polyprotein, ORF2 encoding viral protein (VP) 1, and a partial ORF3 encoding VP2 (Figure 1, panel A). Phylogenetic analysis revealed that the HPNV RNA-dependent RNA-polymerase encoded by ORF1 clustered together with human genogroup I (GI) 

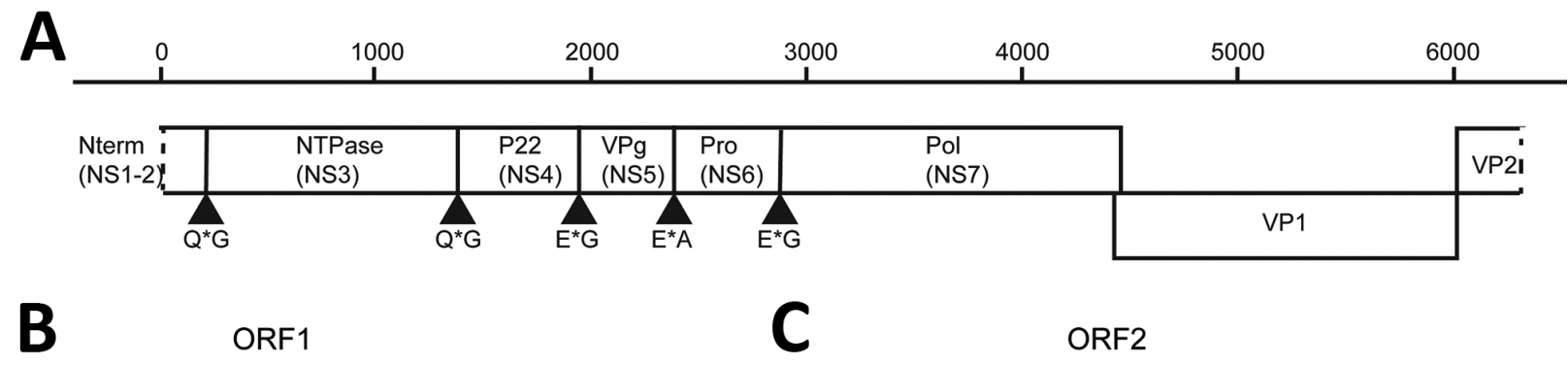

ORF1

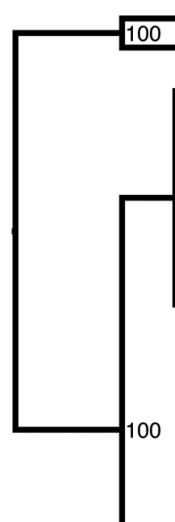

-GV.1_Mu/NoV/GV/MNV1/2002/USA

GV.2_Rn/GV/HKU_CT2/HKG/2011

100 GIII.2_Bo/Newbury2/1976/UK

Harbor porpoise_norovirus

-GI.P1_CVXRNA_Norwalk_virus

-GI.P2_Southampton_virus

[GI.Pb_WUG1

[GI.P6_Norwalk virus

GI.P4_Chiba_virus

1004 GI.P5_Hu/NoV/07_1/2005/SE

-GI.Pc_SzUG1

-GI.P7_Hu/GI.7/S5b/2008/Lilla_Edet/Sweden

_GI.P9_Hu/Chatellerault709/2004/France

GI.Pa_Desert_Shield_virus

_GI.Pf_Hu/GI/Otofuke/1979/JP

FGI.P8_Gl/Hu/JP/2007/GI.P8_Gl.8/Nagoya/KY531

-GI.P3_NLV/NA98115/1998

LGI.Pd_Hu/GI/10360/2010/NNM

Bat_BtRs-CalV/YN2010
GIV.1_HII_dog/GVI.1/HKU_Ca035F/2007/HKG

C ORF2

100 GV_Mu/NoV/GV/MNV1/2002/USA

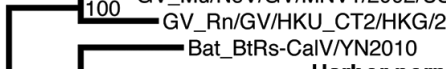

Harbor porpoise_norovirus
GGIIB_Bownewbury2/1976/UK

Harbor porpoise_norovirus
GIII_Bo/Newbury2/1976/UK

[_GIII_sheep/Norsewood30/2007/NZ

- Gl.1_CVXRNA_Norwalk_virus

[GI.6_HU/NLV/Sindlesham/95/UK

-GI.6_Norwalk_virus

CGl.2_Southampton_virus

-Gl.4_Chiba_virus

-GI.5_HU/NLV/Musgrove/89/UK

00-GI.5_SzUG1

- Gl.3_Hu/Akabane/991130/1999/JP/2258

—Gl.3_Hu/GI/Otofuke/1979/JP

-GI.3_Desert_Shield_virus_DSV395

CI.3_NLV/Stav/95/Nor

- GI.8_NLV/Boxer/2001/US

- Gl.9 Hu/GI/Vancouver730/2004/CAN

[Gl.7_Hu/NV/Chiba/030100/2003/JP

[GI.7_HU/NLV/Winchester/94/UK

GI.7 Hu/GI.7/Providence191/2010/USA

-GVII_dog/GVI.1/HKU_Ca026F/2007/HKG

-GVI.1_dog/GVI.1/Bari/91/2007/TTA

GIV.2_dog/FD53/2007/lta

GVI.2_dog/C33/Viseu/2007/PRT

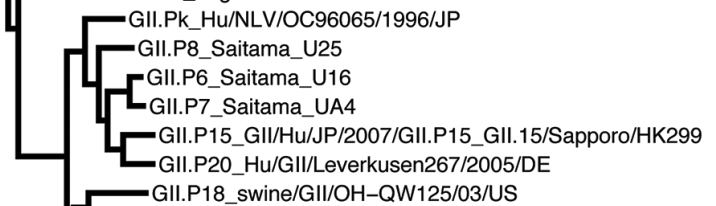

GIll.P11_SW/NV/swine43/JP

GGII.P22_GII/Hu/JP/2001/GII.P22_GIl.5/Saitama/T49

GII.Pn_Hu/Gll.4/Beijing/53931/2007/CHN

_Gll.Pp_Gll/Hu/JP/2011/GIl/Yuzawa/Gira2HS

-GIl.P5_GII/Hu/JP/2002/GII.P5_GII.5/Saitama/T52

_GII.P16_Hu/NLV/GII/Neustrelitz260/2000/D

_Gll.P13_Hu/Pune/PC25/2006/India

-GIII.P3_Saitama_U201

LGII.17_Hu/GII/JP/2015_GII.P17_Gll.17/Kawasaki308

_GII.P2_Hu/MK04/2004/JP

LGII.Pf_Hu/NLV/S63/1999/France

[GII.P21_GII/Hu/JP/2007/GII.P21_GII.21/Kawasaki/YO284

- GII.Pc_Snow_Mountain_virus

LGII.Ph_Hu/OC97007/97/JP

-GII.Pa_SN2000JA

rGII.P1_Hawaii_calicivirus

CGIl.Pm_Hu/Pune/PC24/2006/India

GIII.Pj_Hu/NLV/E3/1997/Crete

-GII.Pe_Hu/GII.4/Sydney/NSW0514/2012/AU

EGII.P4_Hu/GII.4/Hunter504D/04O/AU

LGII.P12_Hu/Sakai/04-179/2005/JP

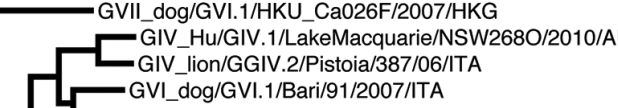

GVI dog/GVI.1/Bar/01/2007/TTA

GVI_dog/C33/Viseu/2007/PRT

_Gll.15_NLV/J23/1999/US

GGII.20_Hu/GII/Luckenwalde591/2002/DE

G Gll.4_Hu/GIl.4/Apeldoorn317/2007/NL

Gll.4_Caliciviridae

Gll.4_Hu/Gll.4/New_Orleans1805/2009/USA

GII.4_Hu/GII.4/Orange/NSW001P/2008/AU

Gll.4_Hu/GIl.4/Sydney/NSW0514/2012/AU

GIll.4_Hu/GIl.4/Sydney/NSW
Gll.3_Minireovirus_TV24

Gll.3_Arg320

GII.3_Hu/GII.3/RotterdamP1D0/2006/NL

[GII.7_HU/NLV/Leeds/90/UK

-GIl.14 NLV/M7/1999/US

—GII.8_Hu/NLV/Amsterdam/98-18/1998/NET

CGII.9_NLV/NA97207/1997

-GII.6a_HU/NLV/Seacroft/90/UK

- Gll.6b_NLV/Miami/292/1994/US

LEll.6c_Hu/Gll.6/8913/Shizuoka/2008/JP

-Gll.18_swine/GII/OH-QW101/03/US

_Gll11_Sw/NLV/Sw918/1997/JP

CGIl.19_swine/GII/OH-QW170/03/US

GIl.17_Hu/NoV/CS-E1/2002/USA

_GII.13_Hu/NLV/Fayetteville/1998/US

_GIl.21_NLV/IF1998/2003//raq

-GII.22_YYRI

—GIll.10_NLV/Erfurt/546/00/DE

EGll.2_Melksham

-Gll.5_HU/NLV/Hillingdon/90/UK

—GIl.16_Hu/NoV/Tiffin/1999/USA

- Gll.1_Hawaii_calicivirus

- GII.12_HU/NLV/Wortley/90/UK

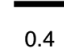

0.6

Figure 1. Genetic characterization of harbor porpoise norovirus. A) Genome organization of harbor porpoise norovirus. The putative cleavage sites are shown with arrowheads. B, C) Maximum-likelihood trees of the RNA-dependent RNA-polymerase (B) and ORF 2 (C) were inferred by PhyML 3.0 software (http://www.atgc-montpellier.fr/phyml/) by using the general time reversible nucleotide substitution model. Selected bootstrap values $>70$ are depicted. Scale bars indicate nucleotide substitutions per site. NS, nonstructural; NTPase, nucleoside triphosphatase; ORF, open reading frame; P, protein; Pol, polymerase; Pro, protease; VP, viral protein. 
sequences (Figure 1, panel B), whereas VP1 clustered near strains belonging to human GI and bovine GIII (Figure 1, panel C).

To determine the tissue tropism of HPNV, we extracted RNA from formalin-fixed paraffin-embedded (FFPE) tissues collected from the HPNV-positive animal for histopathology. Tissues from all main organs and lymph nodes were tested for HPNV RNA by real-time PCR (online Technical Appendix). Only the intestinal tissue and the FFPE material for immunohistochemical analysis (containing a mixture of tissues) were positive for norovirus with cycle threshold values of 30.5 and 37.4, respectively.

We conducted in situ hybridization to determine the cellular tropism of HPNV, as described previously (Figure 2) (12). HPNV-specific transcripts were detected in the cells in the intestine, indicating that this virus replicates in the intestinal tract. Sequential slides stained with hematoxylin and eosin or pankeratin showed that positive cells corresponded with enterocytes that had sloughed into the intestinal lumen because of freeze-thaw artifact, although we cannot exclude the possibility that other cell types were present (Figure 2).

To estimate the percentage of norovirus-infected harbor porpoises in our dataset, we extracted RNA from FFPE porpoise intestinal tissues collected from 48 animals during a 10 -year period. Including the animal in which we detected HPNV, $10 \%(5 / 49)$ of the animals were positive for norovirus (cycle threshold $<37$ ) (Table 1), with primers designed to detect HPNV. Macroscopic and microscopic examination of the intestine of these animals showed no pathologic differences from harbor porpoises without norovirus infection.

To detect norovirus-specific antibodies in porpoise serum, we developed an ELISA based on HPNV VP1 and subsequently screened 34 harbor porpoise serum samples collected during 2006-2015 in the Netherlands (online

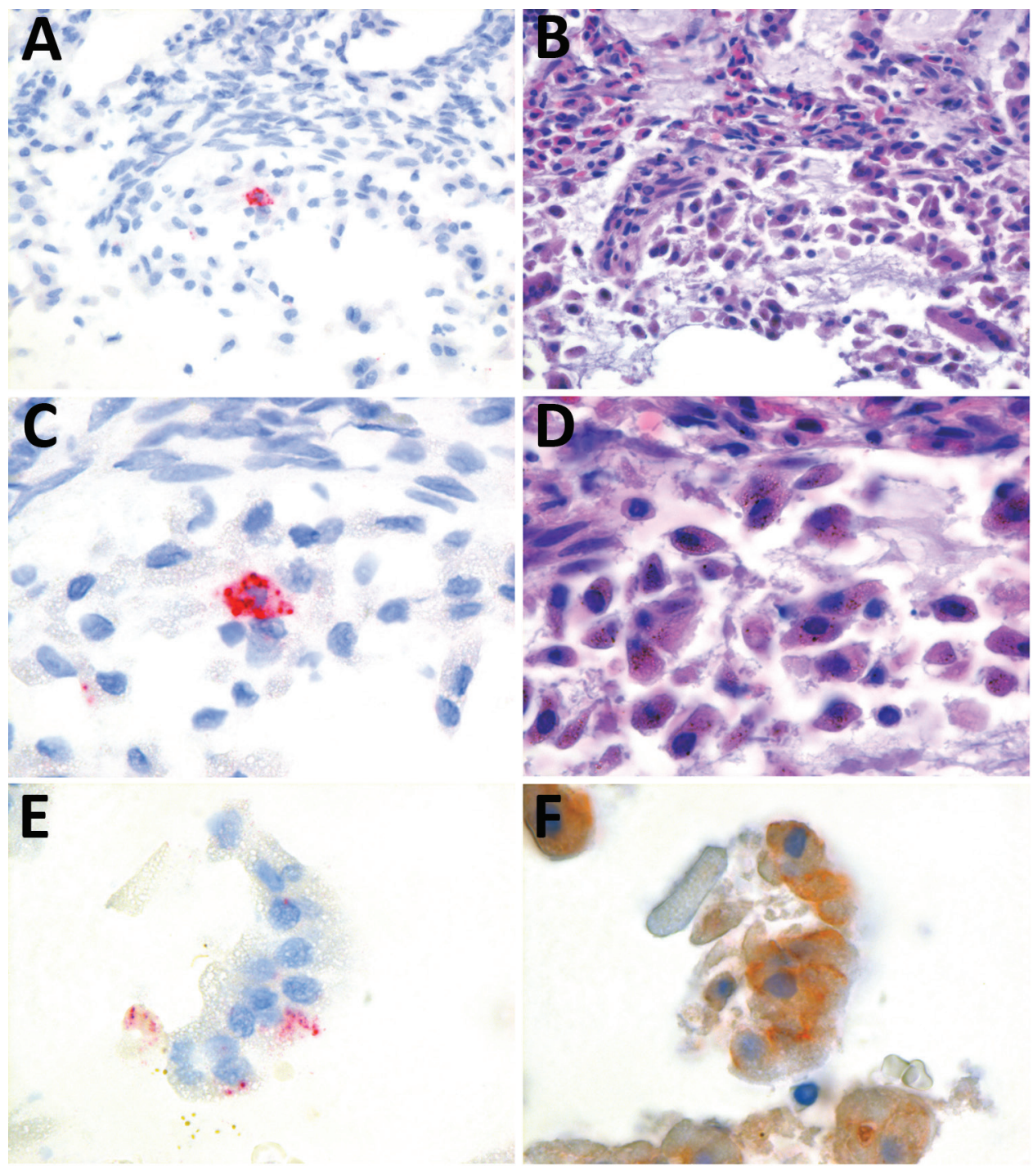

Figure 2. Detection of harbor porpoise norovirus transcripts in intestinal tissue of a harbor porpoise (Phocoena phocoena) using in situ hybridization with probes designed by Advanced Cell Diagnostics (Hayward, CA, USA), based on the 6,293 nt of harbor porpoise norovirus $(A, C, E$; original magnification $\times 40, \times 100, \times 100$, respectively). Consecutive slides were stained with hematoxylin and eosin (B, D; original magnification $\times 40, \times 100$, respectively) and pankeratin $(F$, original magnification $\times 100$ ), as described previously (11). 
Table 1. Formalin-fixed paraffin-embedded tissues subjected to reverse transcription PCR in a study of norovirus in 48 harbor porpoises (Phocoena phocoena), the Netherlands

\begin{tabular}{lccc}
\multicolumn{5}{l}{ porpoises } & (Phocoena phocoena), the Netherlands \\
Year & $\begin{array}{c}\text { Tested } \\
\text { samples, no. }\end{array}$ & $\begin{array}{c}\text { Positive } \\
\text { samples, no. (\%) }\end{array}$ & Cycle threshold \\
\hline 2006 & 12 & 0 & - \\
2007 & 4 & $1(25)$ & 33.8 \\
2008 & 3 & 0 & - \\
2009 & 1 & 0 & - \\
2010 & 4 & 0 & - \\
2011 & 10 & $1(10)$ & 33.8 \\
2012 & 6 & $3(50)$ & - \\
2013 & 4 & 0 & - \\
2014 & 3 & 0 & - \\
2015 & 2 & 0 & \\
\hline
\end{tabular}

Technical Appendix). Samples from 8 (24\%) harbor porpoises were positive for norovirus antibodies (Table 2). This dataset included samples from 2 harbor porpoises that were positive for norovirus RNA; however, their serum samples were negative for norovirus-specific antibodies.

\section{Conclusions}

Similar to human noroviruses, HPNV replicates in the intestine. B cells and enterocytes support human norovirus replication in vitro $(13,14)$. We detected HPNV in cells corresponding to enterocytes, and it will be interesting to determine whether these viruses share receptor use with other noroviruses. In humans, norovirus infections are self-limiting in healthy persons but can result in illness and death in high-risk groups (4). Because the harbor porpoise in which we detected HPNV did not exhibit clinical signs of gastrointestinal disease, norovirus infection probably was not a major factor in the death of this animal.

Remarkably, the HPNV displayed 99\% sequence homology to a short (300-nt) norovirus VP1 sequence detected in oysters (15). These oysters had been sampled because they were associated with a foodborne gastroenteritis outbreak in Ireland in 2012 (15). Oyster samples were collected from the restaurant where the outbreak occurred and from their harvesting area. Strains belonging to genotypes GI.1, GI.4, GII.4, GII.3, GII.1, GII.6, GI.2, GII.7, GI.11, and the strain that was homologous to HPNV were detected, although the HPNV-like strain was detected only in

\begin{tabular}{lccc}
\hline \multicolumn{5}{l}{ Table 2. Prevalence of norovirus-specific antibodies in harbor } \\
porpoises & (Phocoena phocoena), the Netherlands \\
\hline \multicolumn{5}{r}{} & $\begin{array}{c}\text { No. samples } \\
\text { tested }\end{array}$ & $\begin{array}{c}\text { Positive samples, } \\
\text { no. (\%) }\end{array}$ & ELISA titer \\
Year & 12 & $1(8)$ & $\geq 160$ \\
\hline 2006 & 4 & $1(25)$ & 20 \\
2007 & 2 & 0 & \\
2008 & 1 & $1(100)$ & 20 \\
2009 & 5 & $2(40)$ & 40,80 \\
2010 & 5 & $3(60)$ & $20,40,40$ \\
2011 & 1 & 0 & \\
2012 & 0 & 0 & \\
2013 & 1 & 0 & \\
2014 & 1 & 0 & \\
2015 & & & \\
\hline
\end{tabular}

oysters from the harvesting area. In the patients, only GI.4, GI.2, GI.6, GII.1, and GII.7 strains were detected, but the fact that noroviruses infecting marine mammals closely related to human noroviruses have been found infecting harbor porpoises and contaminating oysters raises the question of whether HPNV could infect humans through contamination of oysters or other shellfish.

On the basis of our findings that norovirus infections might be a common infection in harbor porpoises from the southern North Sea and the detection of a norovirus in a sea lion (3), it is not unlikely that noroviruses are common in other marine mammals as well. The high genetic diversity within this genus complicates detection of new noroviruses. The discovery of HPNV and the recent discovery of noroviruses in bats highlight that much still remains to be discovered about animal reservoirs of noroviruses and triggers questions about the zoonotic potential of these viruses.

\section{Acknowledgments}

We thank Peter van Run, Suzanne van Veen, and Lonneke Leijten for excellent technical assistance and SOS Dolphin Foundation for its assistance and support.

This work was supported by the European Union H2020 grant COMPARE under grant agreement no. 643476; the Virgo Consortium, funded by Dutch government project no. FES0908; and the ZonMw TOP grant under grant no. 91213058.

Dr. de Graaf is a research scientist at the Department of Viroscience, Erasmus Medical Center, in Rotterdam. Her primary research interests focus on noroviruses and evolution and determinants of host range.

\section{References}

1. Vinjé J. Advances in laboratory methods for detection and typing of norovirus. J Clin Microbiol. 2015;53:373-81. http://dx.doi.org/10.1128/JCM.01535-14

2. Wu Z, Yang L, Ren X, He G, Zhang J, Yang J, et al. Deciphering the bat virome catalog to better understand the ecological diversity of bat viruses and the bat origin of emerging infectious diseases. ISME J. 2016;10:609-20. http://dx.doi.org/10.1038/ ismej. 2015.138

3. Li L, Shan T, Wang C, Côté C, Kolman J, Onions D, et al. The fecal viral flora of California sea lions. J Virol. 2011;85:9909-17. http://dx.doi.org/10.1128/JVI.05026-11

4. de Graaf M, van Beek J, Koopmans MP. Human norovirus transmission and evolution in a changing world. Nat Rev Microbiol. 2016;14:421-33. http://dx.doi.org/10.1038/ nrmicro.2016.48

5. Bull RA, Hansman GS, Clancy LE, Tanaka MM, Rawlinson WD, White PA. Norovirus recombination in ORF1/ORF2 overlap. Emerg Infect Dis. 2005;11:1079-85. http://dx.doi.org/10.3201/ eid1107.041273

6. Maalouf H, Schaeffer J, Parnaudeau S, Le Pendu J, Atmar RL, Crawford SE, et al. Strain-dependent norovirus bioaccumulation in oysters. Appl Environ Microbiol. 2011;77:3189-96. http://dx.doi.org/10.1128/AEM.03010-10 
7. European Food Safety Authority. The European Union summary report on trends and sources of zoonoses, zoonotic agents and food-borne outbreaks in 2012. EFSA Journal. 2014;12:3547. http://dx.doi.org/10.2903/j.efsa.2014.3547

8. Kuiken T, Baker JR. Guidelines for the post mortem and tissue sampling of cetaceans. In: Law RJ, editor. Fisheries research technical report 97. Lowestoft (UK): Ministry of Agriculture, Fisheries and Food; 1994. p. 5-10.

9. Bodewes R, Rubio García A, Wiersma LC, Getu S, Beukers M, Schapendonk CM, et al. Novel B19-like parvovirus in the brain of a harbor seal. PLoS One. 2013;8:e79259. http://dx.doi.org/10.1371/ journal.pone.0079259

10. Schürch AC, Schipper D, Bijl MA, Dau J, Beckmen KB, Schapendonk CM, et al. Metagenomic survey for viruses in Western Arctic caribou, Alaska, through iterative assembly of taxonomic units. PLoS One. 2014;9:e105227. http://dx.doi.org/ 10.1371/journal.pone.0105227

11. Herfst S, van den Brand JMA, Schrauwen EJA, de Wit E, Munster VJ, van Amerongen G, et al. Pandemic 2009 H1N1 influenza virus causes diffuse alveolar damage in cynomolgus macaques. Vet Pathol. 2010;47:1040-7. http://dx.doi.org/ $10.1177 / 0300985810374836$
12. van Elk C, van de Bildt M, van Run P, de Jong A, Getu S, Verjans $\mathrm{G}$, et al. Central nervous system disease and genital disease in harbor porpoises (Phocoena phocoena) are associated with different herpesviruses. Vet Res (Faisalabad). 2016;47:28. http://dx.doi.org/10.1186/s13567-016-0310-8

13. Ettayebi K, Crawford SE, Murakami K, Broughman JR, Karandikar U, Tenge VR, et al. Replication of human noroviruses in stem cell-derived human enteroids. Science. 2016;353:1387-93. http://dx.doi.org/10.1126/science.aaf5211

14. Jones MK, Watanabe M, Zhu S, Graves CL, Keyes LR, Grau KR, et al. Enteric bacteria promote human and mouse norovirus infection of B cells. Science. 2014;346:755-9. http://dx.doi. org/10.1126/science. 1257147

15. Rajko-Nenow P, Keaveney S, Flannery J, McINTYRE A, Doré W. Norovirus genotypes implicated in two oyster-related illness outbreaks in Ireland. Epidemiol Infect. 2014;142:2096-104. http://dx.doi.org/10.1017/S0950268813003014

Address for correspondence: Miranda de Graaf, Erasmus Medical Center-Viroscience, Wytemaweg 80 Rotterdam 3015CN, the

Netherlands; email: m.degraaf@erasmusmc.nl

\section{December 2015: Zoonotic Infections}

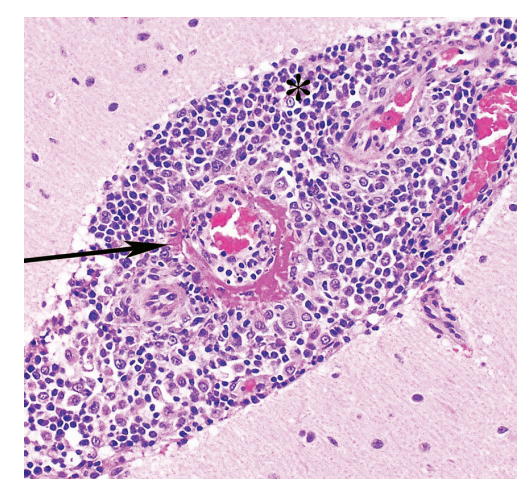

- Identifying and Reducing Remaining Stocks of Rinderpest Virus

- Opportunistic Pulmonary Bordetella hinzii Infection after Avian Exposure

- Zoonotic Leprosy in the Southeastern United States

- Infection Risk for Persons Exposed to Highly Pathogenic Avian Influenza A H5 Virus-Infected Birds, United States, December 2014 March 2015

- High Prevalence of Intermediate Leptospira spp. DNA in Febrile Humans From Urban and Rural Ecuador
- Biological Warfare Plan in the 17th Century-the Siege of Candia, 1648-1669

- Influenza A(H6N1) Virus in Dogs, Taiwan

- Methicillin-Resistant Staphylococcus aureus Prevalence among Captive Chimpanzees, Texas, USA, 2012

- Novel Waddlia Intracellular Bacterium in Artibeus intermedius Fruit Bats, Mexico

- Tembusu-Related Flavivirus in Ducks, Thailand

- Japanese Macaques (Macaca fuscata) as Natural Reservoir of Bartonella quintana

- Onchocerca lupi Nematode in a Cat, Europe

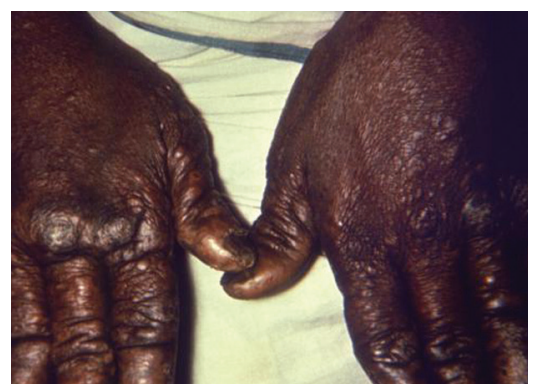

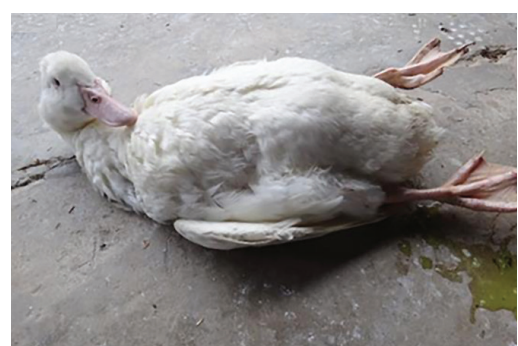

- Increased Number of Human Cases of Influenza Virus A(H5N1) Infection, Egypt, 2014-15

- Replication Capacity of Avian Influenza A(H9N2) Virus in Pet Birds, Chickens, and Mammals, Bangladesh

- Hendra Virus Infection in Dog, Australia, 2013

- No Evidence of Gouléako and Herbert Virus Infections in Pigs, Côte d'Ivoire and Ghana

- Aquatic Bird Bornavirus 1 in Wild Geese, Denmark

- Vectorborne Transmission of Leishmania infantum from Hounds, United States

- Porcine Deltacoronavirus in Mainland China
EMERGING INFECTIOUS DISEASES

\section{http://wwwnc.cdc.gov/eid/articles/ issue $/ 21 / 12 /$ table-of-contents}

